\title{
ACORDOS AMBIENTAIS ENTRE EMPRESAS, RESPONSABILIDADE SOCIAL CORPORATIVA E CONCORRÊNCIA
}

\author{
LÍGIA CARVALHO ABREU \\ PROFESSORA ASSOCIADA DA FACULDADE DE DIREITO DA ULP \\ MEMBRO DO CENTRO DE ESTUDOS AVANÇADOS EM DIREITO (CEAD) \\ MEMBRO DO CENTRO DE INVESTIGAÇÃO E DESENVOLVIMENTO SOBRE DIREITO \\ E SOCIEDADE (CEDIS)
}

\begin{abstract}
Environmental agreements between companies are the expression of a way of acting together to fulfill, voluntarily or by legal requirement, environmental goals, such as reducing pollution or fighting climate change. However, under European Union law, the acceptance of those agreements depends on their compliance with competition rules, as they must not affect trade between member states. Thus, this article reflects on the importance of environmental agreements between companies as cooperation instruments that strengthen corporate social responsibility and the extent to which they are compatible with European Union's competition law.
\end{abstract}

KEYWORDS: Agreements, environment, companies, competition

SUMÁRIO: Introdução; 1. Acordos ambientais: suas características e importância na definição de uma política de responsabilidade social corporativa consistente; 2. Acordos ambientais e as restrições à concorrência; 2.1 A restrição sensivel à concorrência; 2.2 Integração das preocupações ambientais no direito da concorrência; Conclusão.

RESUMO: os acordos ambientais entre empresas são a expressão de um modo de actuar em comum para cumprir, de forma voluntária ou em virtude da existência de uma imposição legal, objectivos ambientais, tais como a redução da polvição ou o combate às alterações climáticas. No entanto, à luz do direito da União Europeia a aceitação de tais acordos depende da sua conformidade com as regras da concorrência, pois não devem afectar o comércio entre os Estados-Membros. Neste sentido, o presente artigo reflecte sobre a importância dos acordos ambientais entre empresas como instrumentos de cooperação que fortalecem a responsabilidade social corporativa e em que medida eles são compatíveis com o direito da concorrência da União Europeia.

KEYWORDS: acordos, ambiente, empresas, concorrência

INTRODUC̣ÃO: As ações das empresas repercutem-se na vida dos cidadãos de diversas formas e, por conseguinte, estas não devem ser alheias ao que se passa na sociedade. De acordo com o modelo tridimensional de desempenho corporativo definido por Archie Carrol ${ }^{1}$, a responsabilidade social da empresa possui quatro dimensões:

- A responsabilidade económica traduz-se num compromisso da empresa para com sociedade baseado nas suas necessidade de bens e serviços e no lucro gerado por este consumo. Por outras palavras, a empresa é criada para produzir bens e prestar serviços que a sociedade necessita. Assim, a sua finalidade é a obtenção do lucro de forma a garantir a continuidade das suas atividades. O lucro é a razão da existência das empresas.

- A responsabilidade legal define-se pelo compromisso com a lei.

- A responsabilidade ética traduz-se no dever de ação em conformidade com valores morais, não necessariamente previstos na lei. Neste contexto, a empresa assume um compromisso, para com a sociedade, de abolir comportamentos antiéticos que comprometam a transparência e a justiça nas relações económicas.

\footnotetext{
I Cf. CARROL, Archie (1979). "A three dimensional conceptual model of corporate performance". Academy of Management Review (pre-1986); 4; ABI/INFORM.

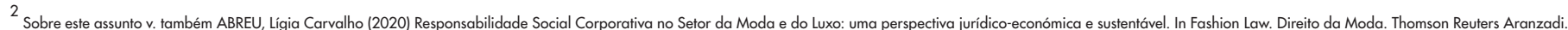


DOI: 10.46294/ulplr-rdulp.siv la 1

- Por fim, a responsabilidade discricionária associada às ações voluntárias de filantropia das empresas, como por exemplo doações a instituições sociais, mecenato artístico ou financiamento de projetos comunitários que, apesar de não serem inicialmente considerados lucros, nem destes se esperar nenhum retorno, fazem parte da imagem da empresa e como tal têm impacto no rendimento esperado, em virtude do posterior desenvolvimento do marketing, da publicidade e das novas tecnologias. ${ }^{2}$

É no contexto das dimensões legal e ética da responsabilidade social que enquadramos a questão da compatibilidade dos acordos ambientais entre empresas com as regras da concorrência, acrescentando ainda, à responsabilidade corporativa, a dimensão de cooperação entre empresas concorrentes para uma melhor eficácia na resposta aos problemas ambientais globais.

\section{Acordos Ambientais: suas características e importância na definição de uma política de responsabilidade social corporativa consistente}

Os acordos ambientais existentes nos mais diversos sectores e conómicos (pasta de papel, resíduos, embalagens etc..) são formas de entendimento entre empresas e outros parceiros sociais ${ }^{3}$ sobre o modo de actuar em comum para cumprir, de forma voluntária ou em virtude da existência de uma imposição legal, objectivos de natureza ambiental, como por exemplo reduzir a poluição, combater as alterações climáticas, utilizar de forma racional os recursos naturais, entre outros. ${ }^{4}$ Por exemplo, empresas concorrentes do sector agro-industrial celebram um acordo mediante o qual se comprometem a reduzir a utilização de plástico ou eliminar uma técnica de produção para reduzir as emissões de gases com efeito de estufa. Assim definidos, os acordos ambientais são instrumentos de cooperação. Desta forma, não obstante a competitividade e concorrência natural entre empresas, a cooperação entre estas deve fazer parte de uma política de responsabilidade corporativa, pois sem ela não se encontrará uma solução verdadeiramente eficaz para os desafios globais de natureza ambiental.

Os acordos ambientais podem ser classificados segundo vários critérios. Indicamos alguns dos mais relevantes. Segundo o critério que tem em conta a natureza das partes envolvidas, os acordos podem ser horizontais ou verticais consoante forem celebrados entre produtores de uma categoria específica de produto, por exemplo entre produtores de papel ou entre diferentes actores económicos em relação a um determinado bem (por exemplo, os produtores de embalagens, os distribuidores e os responsáveis pelo seu tratamento e reciclagem). Em virtude da natureza e fundamento das obrigações previstas, os acordos ambientais podem ser voluntários e resultar de práticas de auto-regulação ${ }^{5}$ ou seja de decisões espontâneas das empresas, por sua própria iniciativa, no sentido de regular e organizar as suas actividades em prol do desenvolvimento sustentável sem que exista um acto normativo que imponha o cumprimento de objectivos ambientais por meio destes acordos.

Os acordos ambientais podem também resultar de práticas de co-regulação por parte dos Estados ou de organizações internacionais. Por exemplo, de acordo com a Comunicação da Comissão ao Parlamento Europeu, ao Conselho, ao Comité Económico e social e ao Comité das Regiões - Acordos Ambientais concluídos a nível comunitário no âmbito do Plano de Acção "Simplificar e melhorar o ambiente regulador, a Comissão pode promover e reconhecer os acordos ambientais resultantes de práticas de auto-regulação, como também, por sua iniciativa ou como resposta à indústria, "propor a sua utilização ao legislador (co-regulação)". ${ }^{5}$ Neste âmbito, o legislador fixa os aspectos essenciais do conteúdo desses acordos, tais como os objectivos, os prazos de cumprimento, os mecanismos de implementação e de monotorização, entre outros. Os acordos ambientais entre empresas que resultam da actividade de co-regulação são a expressão de um compromisso vinculativo para com o cumprimento das normas da União Europeia por parte dos actores envolvidos no acordo.

Desta forma, aos acordos ambientais podem ser instrumentos relevantes no cumprimento da legislação por parte das empresas e funcionar como complemento de outros instrumentos económicos, políticos e legislativos, direccionando a

\footnotetext{
${ }^{3}$ Importa referir que estes acordos podem ser celebrados entre empresas mas também entre estas e organizações não-governamentais ou outros parceiros sociais.

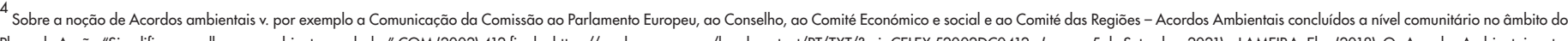

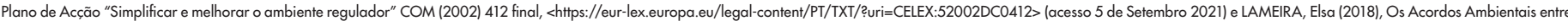

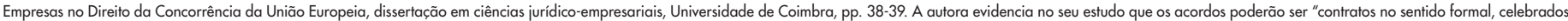

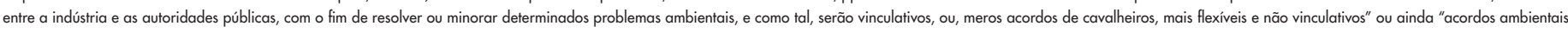

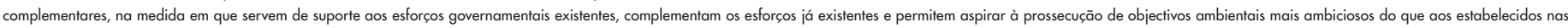
diferentes regulações."

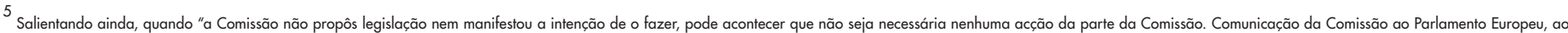
Conselho, ao Comité Económico e social e ao Comité das Regiões - Acordos Ambientais concluídos a nível comunitário no âmbito do Plano de Acção, p.7.

${ }^{6}$ Idem.
} 
DOI: $10.46294 /$ ulplr-rdulp.sivla 1

empresa, como centro de poder, para a promoção do desenvolvimento sustentável. 7

Através dos acordos ambientais as empresas podem se comprometer a reduzir o nível de emissões poluentes, a abandonar um método ou material polvente, a introduzir processos ou materiais ecológicos, a utilizar energias renováveis, a desenvolver novas tecnologias ou a utilizar a melhor tecnologia disponível. Tais condutas conjuntas são a expressão do desenvolvimento científico e da inovação que propicia uma maior qualidade e possibilidade de escolha dos produtos, por parte dos consumidores, contribuindo assim para o fomento da responsabilidade social corporativa porque esta engloba todas as medidas éticas e de cumprimento da lei que a empresa adota como forma de manifestar o seu compromisso, para com a sociedade, de fomento dos valores humanos e de proteção do ambiente. Uma empresa com política de responsabilidade social não abandona o lucro como seu objetivo, mas faz ascender ao patamar do lucro a finalidade de respeito da lei, dos valores éticos e das ações voluntárias, ao encontro de uma sociedade justa e sustentável para as gerações presentes e futuras. Assim, a responsabilidade corporativa tem uma função social que limita o direito dos proprietários e acionistas ao lucro a favor dos stakeholders e do bem comum da sociedade, função social que os acordos ambientais podem ajudar a cumprir. Na prática tal concepção apela ao agir de forma concreta, promovendo a evolução do homem de acordo com uma perspetiva biocêntrica do mundo em que vive, através, por exemplo da produção de bens ecológicos ou com outro valor social, da promoção de consumos mais sustentáveis, da adoção de tecnologia limpa, etc.... ${ }^{8}$

$\bigcirc$ crescimento e permanência no mercado e a conquista de novos mercados são fins alcançáveis quando a empresa consegue transmitir a sua política de responsabilidade social aos consumidores através da publicidade aos seus produtos, serviços e ações. A imagem e a identidade da empresa ${ }^{9}$ passaram a ser trabalhadas tendo por base a responsabilidade social corporativa, com o objetivo de melhor comunicar com o seu público-alvo. Os acordos ambientais entre empresas podem também ser utilizados como forma de projectar a imagem e identidade da empresa.

\section{Os Acordos Ambientais e as Restrições à Concorrência}

Como foi referido as empresas podem encontrar nos acordos ambientais uma forma de impulsionar os seus objectivos económicos, de inovação e ambientais. No entanto, como bem nota Elsa Lameira, as empresas com maior capacidade de produção e recursos, "ao estabelecer no acordo novos métodos de produção mais tecnológicos, ou o desenvolvimento de produtos mais eficientes, por exemplo, dificultam a concorrência por parte das empresas mais pequenas, e a própria entrada no mercado por parte de novos operadores". ${ }^{10}$

artigo $101 n^{\circ} 1$ do Tratado de Funcionamento da União Europeu (TFUE) dispõe que "São incompatíveis com o mercado interno e proibidos todos os acordos ${ }^{11}$ entre empresas $^{12}$, todas as decisões de associações de empresas ${ }^{13}$ e todas as práticas concertadas que sejam suscetíveis de afetar o comércio entre os Estados-Membros e que tenham por objetivo ou efeito impedir, restringir ou falsear a concorrência no mercado interno, designadamente as que consistam em:

a) Fixar, de forma direta ou indireta, os preços de compra ou de venda, ou quaisquer outras condições de transação;

b) Limitar ou controlar a produção, a distribuição, o desenvolvimento técnico ou os investimentos;

c) Repartir os mercados ou as fontes de abastecimento;

d) Aplicar, relativamente a parceiros comerciais, condiç̃̃es desiguais no caso de prestações equivalentes colocando-os, por esse facto, em desvantagem na concorrência;

e) Subordinar a celebração de contratos à aceitação, por parte dos outros contraentes, de prestações suplementares que, pela sua natureza ou de acordo com os usos comerciais, não têm ligação com o objeto desses contratos." São assim nulos todos os acordos proibidos por esta disposição lartigo 101 n² do TFUE). Ainda nos termos do artigo 102 do TFUE.

"É incompatível com o mercado interno e proibido, na medida em que tal seja suscetível de afetar o comércio entre os Estados-Membros, o facto de uma ou mais empresas explorarem de forma abusiva uma posição dominante no mercado interno

\footnotetext{
7 Nom No mesmo sentido v. Comunicação da Comissão ao Parlamento Europeu, ao Conselho, ao Comité Económico e social e ao Comité das Regiões - Acordos Ambientais concluídos a nível comunitário no âmbito do Plano de Acção "Simplificar e

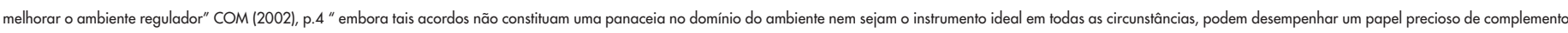
- mas não de substituto - de outros instrumentos políticos, nomeadamente legislação".

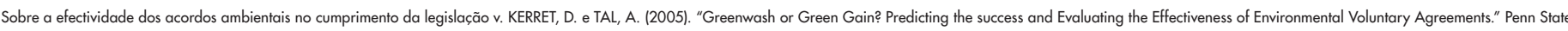

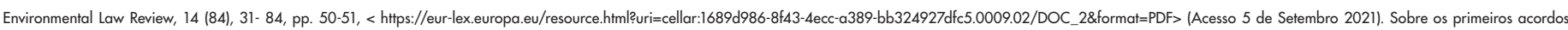

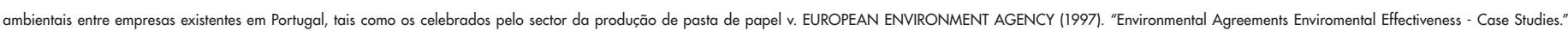

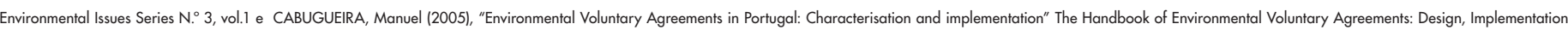
and Evaluation Issues. E. Croci (Ed.), pp. 203-219.
} 
DOI: 10.46294/ulplr-rdulp.siv la 1

ou numa parte substancial deste. Estas práticas abusivas podem, nomeadamente, consistir em:

a) Impor, de forma direta ou indireta, preços de compra ou de venda ou outras condições de transação não equitativas;

b) Limitar a produção, a distribuição ou o desenvolvimento técnico em prejuízo dos consumidores;

c) Aplicar, relativamente a parceiros comerciais, condições desiguais no caso de prestações equivalentes colocando-os, por esse facto, em desvantagem na concorrência;

d) Subordinar a celebração de contratos à aceitação, por parte dos outros contraentes, de prestações suplementares que, pela sua natureza ou de acordo com os usos comerciais, não têm ligação com o objeto desses contratos."

Em conformidade com os referidos artigos, os acordos podem ter finalidade restringir a concorrência ou produzir o efeito de restringir a concorrência. Quando um acordo tem por objectivo restringir a concorrência através, por exemplo, da fixação de preços, os seus efeitos negativos, tais como a redução da produção e da disponibilidade de bens no mercado, repercutem-se na sociedade. Tal situação gera um aumento dos preços, sendo desfavorável para os consumidores. Os acordos ambientais que prosseguem estes objectivos são proibidos pelo TFUE. Quando os acordos entre empresas não tem por objectivo restringir a concorrência mas produzem esse efeito de forma real ou potencial, afectando o mercado ao nível dos preços dos produtos ou da disponibilidade e qualidade dos produtos e serviços, tais acordos são também proibidos pelo TFUE.

Da leitura dos referidos artigos se depreende que a sua aplicação depende da verificação cumulativa dos requisitos ai mencionados, o que significa que os acordos ambientais entre empresas apenas são proibidos se afectarem as regras da concorrência no mercado interno da União Europeia e por conseguinte restringirem de forma sensível o comércio intercomunitário ${ }^{14}$ porque o objectivo inerente ao TFUE, neste contexto, é "proteger a concorrência no mercado, como forma de reforçar o bem-estar dos consumidores e de assegurar uma eficiente afetação de recursos". ${ }^{15}$

\subsection{A Restrição Sensível à Concorrência}

Os acordos ambientais não podem restringir de forma sensivel as relações comerciais entre Estados membros. Este é o entendimento tanto da Comissão ${ }^{16}$ como do TJUE 17 e que justifica a proibição do acordo ao abrigo do artigo $101 n^{\circ} 1$ do TFUE. Tal impacto no comércio interno é avaliado tendo em conta "as circunstâncias específicas do caso concreto, nomeadamente da natureza do acordo ou prática, da naturezadosprodutosabrangidoseda posiçãodemercadodasempresasemcausa. (...) Quanto mais forte for a posição de mercado das empresas em causa, maior é a probabilidade de um acordo ou prática susceptível de afectar o comércio entre os Estados-Membros o vir a afectar de forma sensível "18

Por exemplo, de acordo com jurisprudência do TJUE, as vendas das empresas que

${ }^{8}$ Cf. ABREU, Lígia Carvalho (2020) Responsabilidade Social Corporativa no Setor da Moda e do Luxo: uma perspectiva jurídico-económica e sustentável. In Fashion Law. Direito da Moda. Thomson Reuters Aranzadi

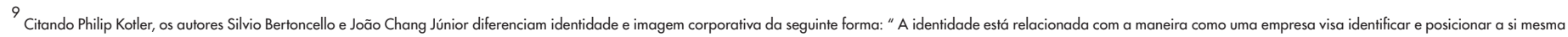

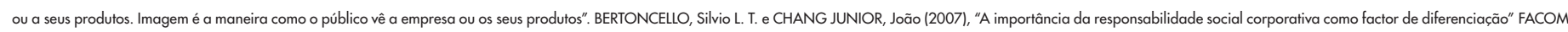
n. 17,1 semestre, p. 75$)$

${ }^{10}$ Cf. LAMEIRA, Elsa (2018), Os Acordos Ambientais entre Empresas no Direito da Concorrência da União Europeia. Disserłação em ciências jurídico empresariais, Universidade de Coimbra, p. 10.

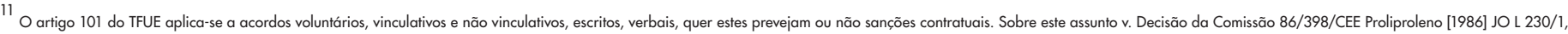

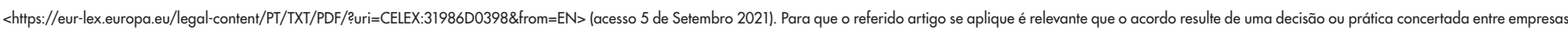
ou um entendimento comum, por parte destas, sobre elementos do acordo no sentido de o implementarem.

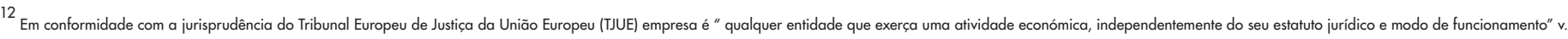
por exemplo Acórdão C-41/90, Höfner \& Elser v. Macrotron, [1991], parágrafo. 21, <https://eur-lex.europa.eu/resource.htmleuri=cellar:1689d986-8f43-4ecc-a389-bb324927dfc5.0009.02/DOC_28format=PDF> (Acesso 5 de Setembro 2021).

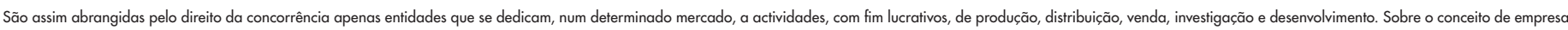

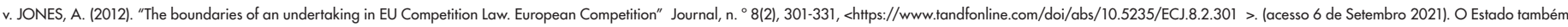

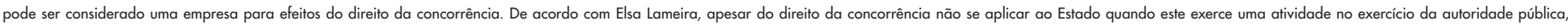

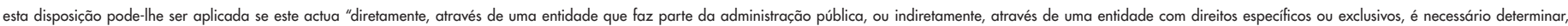

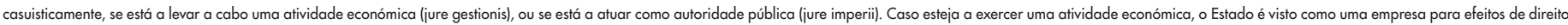

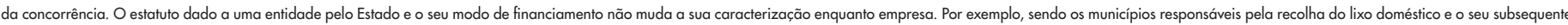

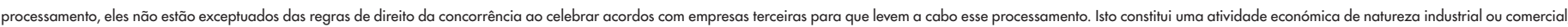

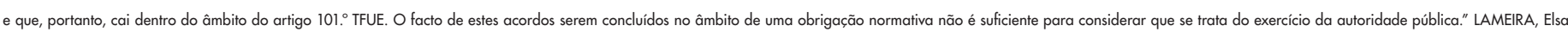

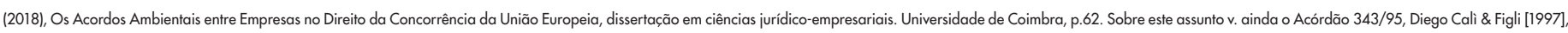

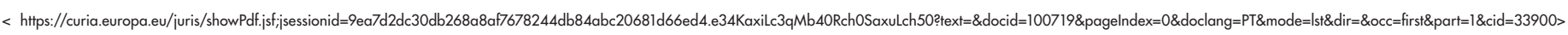
(Acesso 5 de Setembro 2021). 
DOI: 10.46294/ulplr-rdulp.siv la 1

representam 5\% do mercado podem afectá-lo de forma sensivel. ${ }^{19}$ Já se o acordo for vertical ${ }^{20}$ a restrição à concorrência só será sensivel se a quota de mercado onde são vendidos os bens ou serviços de cada uma das partes no acordo ultrapassar os $30 \%$. ${ }^{21}$ Num outro caso sobre um acordo que tinha por objectivo fixar padrões de eficiência energética para máquinas de lavar roupa, celebrado entre os fabricantes de electrodomésticos e organizações comerciais nacionais membros da associação belga CECED, a Comissão considerou que o acordo violava as regras da concorrência uma vez que as partes detinham $95 \%$ de quota de mercado relevante, quando "nenhuma forma alternativa de lavagem como, por exemplo, a lavagem à mão, as lavandarias, a limpeza a seco e as máquinas de propriedade colectiva podem substituir, num grau significativo, as máquinas de lavar roupa nos países ocidentais. Consequentemente, não pode ser delineado um mercado do produto mais vasto por forma a incluir outros electrodomésticos num único mercado do produto". ${ }^{22}$

Assim, a quota de mercado é um elemento relevante para determinar se o acordo viola o direito da concorrência, nomeadamente se existe abuso de posição dominante ou se falseia a concorrência no mercado interno ${ }^{23}$, mas não é o único factor decisivo. É necessário ter em conta outros elementos, incluindo a natureza dos produtos ou serviços, os mercados de produtos e serviços relevantes ${ }^{24}$, a relevância e o número de empresas num determinado mercado geográfico ${ }^{25}$ e volume dos seus negócios. ${ }^{26}$

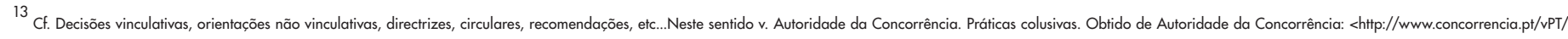
Praticas_Proibidas/Praticas_Restritivas_da_Concorrencia/Praticas_Colusiva s/Paginas/Praticas-colusivas.aspx > (Acesso 5 de Setembro 2021).

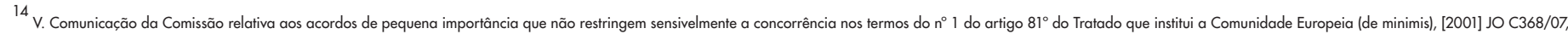

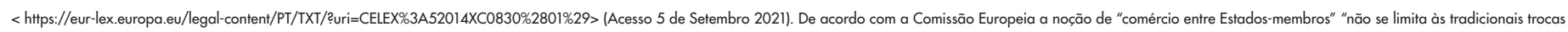

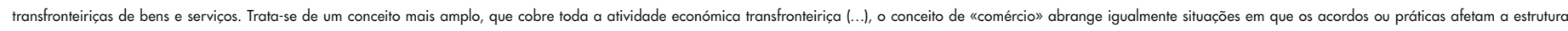

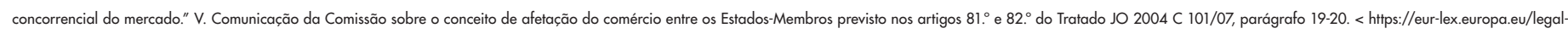
content/PT/TXT/PDF/?uri=CELEX:52004XC0427(06)\&from=DA> (Acesso 5 de Setembro 2021).

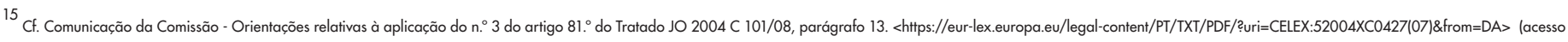
5 de Setembro 2021).

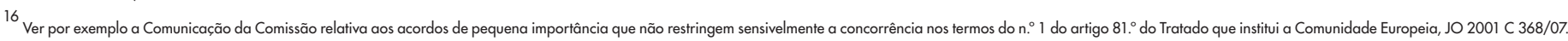

17 Cf. Acórdão C-5/69, Völk v. Vervaeckel [1969], parágrafos 5 a 7.

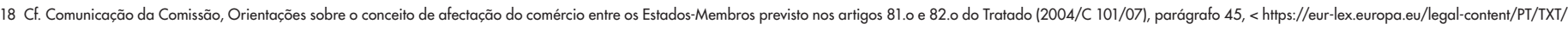
PDF/?uri=CELEX:52004XC0427(06)\&from=DA> (acesso 6 de Setembro 2021)

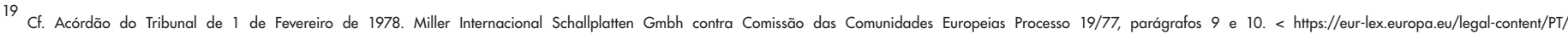
TXT/? Uri=CELEX\%3A61977CJ0019> (acesso 6 de Setembro 2021).

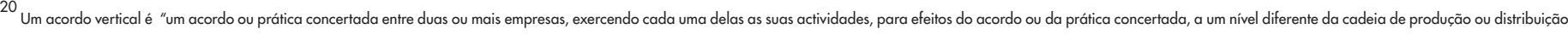

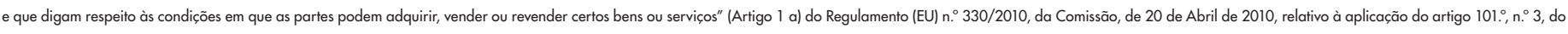
TFUE a determinadas categorias de acordos verticais e práticas concertadas, JO 2010 L 102/1. <https://eur-lex.europa.eu/legal-content/PT/TXT/2uri=CELEX\%3A32010R0330> (acesso 6 de Setembro 2021).

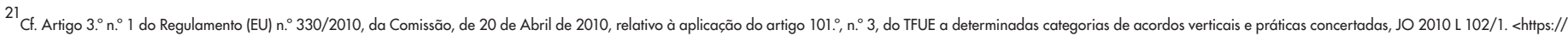
eur-lex.europa.eu/legal-content/PT/TXT/?uri=CELEX\%3A32010R0330> (acesso 6 de Setembro 2021).

${ }^{22}$ Cf. Decisão da Comissão 2000/475/EC CECED [2000] L 187/47, paragrafo 42. <https://eur-lex.europa.eu/LexUriServ/LexUriServ.do?uri=OJ:L:2000:187:0047:0054:PT:PDF> (acesso 6 de Setembro de 2021).

${ }^{23}$ CF. HILDEBRAND, D. (2009). The Role of Economic Analysis in the EC Competition Rules. Wolters Kluwer, pp. 230-231.

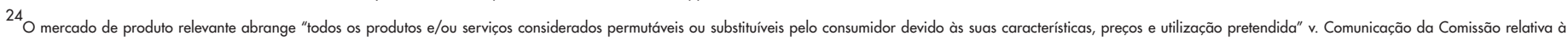

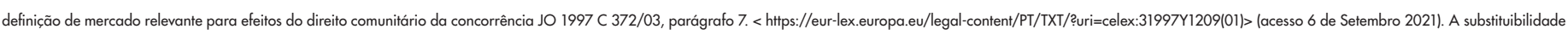

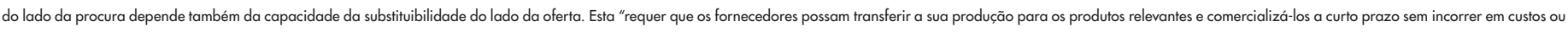

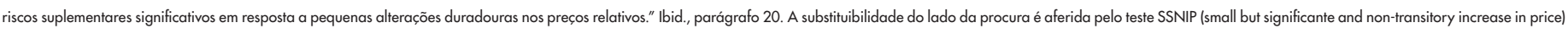

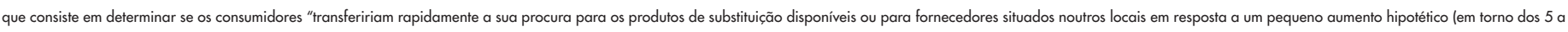


DOI: 10.46294/ulplr-rdulp.siv la 1

\subsection{Integração das Preocupações Ambientais no Direito da Concorrência}

Apesar dos acordos ambientais estarem limitados pelos artigos 101 e 102 do TFUE, as regras da concorrência têm de ser interpretadas e aplicadas em conformidade com os objectivos de proteção do ambiente explanados no artigo 3 do Tratado da União Europeia (TUE) nos seguintes termos, a União "empenha-se no desenvolvimento sustentável da Europa, assente num crescimento económico equilibrado e na estabilidade dos preços, numa economia social de mercado altamente competitiva que tenha como meta o pleno emprego e o progresso social, e num elevado nível de proteção e de melhoramento da qualidade do ambiente (...".

Assim, as regras de concorrência não devem ser de tal forma estritas que impeçam a inovação tecnologia capaz de contribuir para a resolução dos problemas ambientais, como a poluição ou as alterações climáticas, através da criação de novos produtos, processos e serviços mais ecológicos.

Desta forma, o artigo 101 n 3 do TFUE não proíbe acordos ambientais que contenham restrições à concorrência se estas contribuírem "para melhorar a produção ou a distribuição dos produtos ou para promover o progresso técnico ou económico, contanto que aos utilizadores se reserve uma parte equitativa do lucro daí resultante; não imponham às empresas em causa quaisquer restrições que não sejam indispensáveis à consecução desses objectivos nem dêem a essas empresas a possibilidade de eliminar a concorrência relativamente a uma parte substancial dos produtos em causa". Assim, da mesma forma que a luz dos artigos 34 e 36 do TFUE a livre circulação de mercadorias pode se restringida por motivo de proteção do ambiente, a proteção do ambiente também pode ser utilizada como argumento para restringir a concorrência ${ }^{27}$, desde que respeitados certos limites.

A produção de produtos sem plástico ou a eficiência energética, entre outros, acarretam benefícios ambientais, bem como contribuem para o progresso económico e técnico. Acordos ambientais que fomentam a inovação dão origem a novos produtos e de melhor qualidade, pelo que promovem "a essência do processo concorrencial, nomeadamente ao permitirem às empresas conquistar novos clientes graças à oferta de melhores produtos ou melhores preços do que os oferecidos pelos concorrentes. ${ }^{28}$

No entanto, de forma a permitir um acordo ambiental à luz do $n^{\circ} 3$ do artigo 101 do TFUE os benefícios para os consumidores, que este acordo visa alcançar, devem ser superiores às desvantagens que estes provocam na concorrência. É neste contexto que se explica o sentido da expressão "contanto que aos utilizadores se reserve uma parte equitativa do lucro daí resultante". 29 Por exemplo, no supra referido acordo celebrado entre fabricantes de electrodomésticos e organizações comerciais nacionais membros da associação belga CECED, a Comissão considerou que "muito embora o acordo elimine as classes de produto e os modelos que se enquadrem nas classes $D$ e outras inferiores, não é possível determinar a priori os seus efeitos sobre o preço de venda médio das categorias

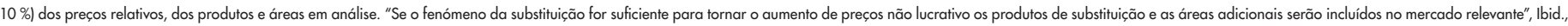

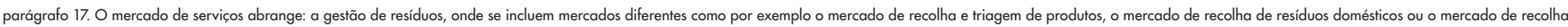

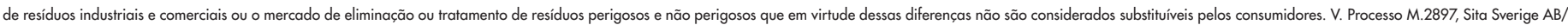
Sydkraft Ecoplus, 14 de Outubro de 2002, parágrafo 10 e 11. < https://ec.europa.eu/competition/mergers/cases/decisions/m2897_en.pdf> (acesso 6 de Setembro 2021).

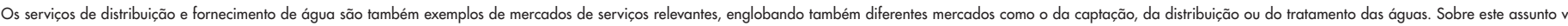
LAMEIRA, Elsa (2018), Os Acordos Ambientais entre Empresas no Direito da Concorrência da União Europeia, dissertação em ciências jurídico-empresariais, Universidade de Coimbra, pp. 68-69.

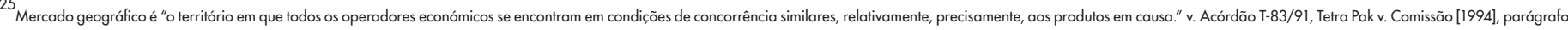
91; < https://eur-lex.europa.eu/legal-content/PT/TXT/HTML/?uri=CELEX:61991TJ0083\&from=PT> (acesso 6 de Setembro 2021) e ainda

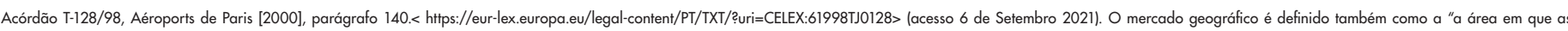

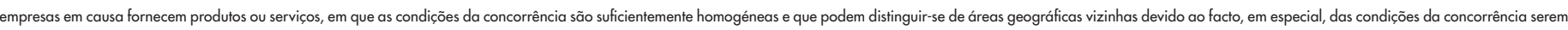
consideravelmente diferentes nessas áreas." V. Comunicação da Comissão relativa à definição de mercado relevante para efeitos do direito comunitário da concorrência JO 1997 C $372 / 03$, parágrafo 8.

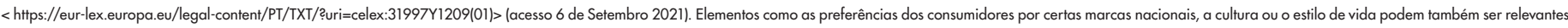

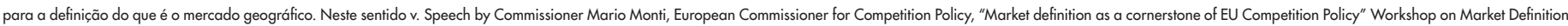
- Helsinki Fair Centre, Helsinki, 5 October 2001 < https://ec.europa.eu/commission/presscorner/detail/en/SPEECH_01_439> (acesso 5 de Setembro 2021).

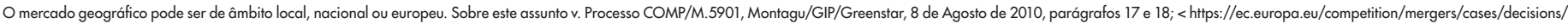
m5901_222_2.pdf> ou Processo COMP/M.2897, Sita Sverige AB/Sydkraft Ecoplus, parágrafo 14; <https://ec.europa.eu/competition/mergers/cases/decisions/m2897_en.pdf> (acesso 6 de Setembro 2021).

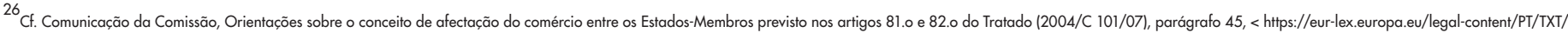
PDF/?uri=CELEX:52004XC0427(06)\&from=DA> (acesso 6 de Setembro 2021). 
DOI: 10.46294/ulplr-rdulp.siv la 1

e modelos das máquinas de lavar que não sejam directamente afectadas. Com efeito, a restrição a nível de uma dimensão do produto, a saber, o consumo de energia, pode intensificar a concorrência a nível de outras características do produto, nomeadamente, em matéria de preços. Por conseguinte, embora o preço mínimo das máquinas de lavar seja susceptível de aumentar, não é de excluir que os produtos pertencentes às classes $A$ e $B$ possam vir a ser comercializadas a um preço mais baixo. Num mercado caracterizado por uma concorrência intensa entre os fabricantes e por uma capacidade negocial da parte dos distribuidores, é provável que estes benefícios se revertam em benefício dos consumidores." 30 Efectivamente, este acordo fixa um objectivo de redução do consumo de energia de pelo menos 15 a 20\%. ${ }^{31}$ Estimou-se que o cumprimento do acordo faria reduzir a polvição "em 3,5 milhões de toneladas de dióxido de carbono, em 17 quilotoneladas de dióxido de enxofre e 6 quilotoneladas de óxido nitroso por ano em 2010, com base nos dados médios de emissão." 32 Para a Comissão as máquinas de lavar que consomem menos electricidade são "em termos objetivos, tecnicamente mais eficientes. Um menor consumo de energia eléctrica desencadeia automaticamente uma redução da poluição resultante da produção de electricidade". ${ }^{33}$

A investigação e desenvolvimento que este acordo incentiva traduzir-se-iam num efectivo progresso técnico e económico, conferindo vantagens individuais e colectivas para os utilizadores e consumidores. Nas palavras da Comissão, este acordo centra "a futura investigação e desenvolvimento na melhoria de eficiência energética, superando os actuais limites tecnológicos da classe $A$, permitindo assim uma maior diferenciação dos produtos entre os produtores a longo prazo (..). $\bigcirc$ nível a que é fixado a norma de eficiência mínima prevê uma remuneração equitativa dentro de um período de reembolso razoável para os consumidores individuais face aos custos de aquisição iniciais mais elevados resultantes da norma mais rigorosa estabelecida doravante pelo CECED. As economias a nível das facturas de electricidade permitirão compensar os custos acrescidos das máquinas melhoradas e mais onerosas num prazo de nove a quarenta meses, em função sobretudo da frequência de utilização e dos preços em matéria de electricidade." ${ }^{\prime \prime 4}$ Ponderados, os custos e os benefícios do acordo, a Comissão considerou que "os benefícios para a sociedade desencadeados pelo acordo CECED afiguram-se ser sete vezes superiores aos custos de aquisição acrescidos das máquinas de lavar, mais eficientes do ponto de vista do consumo de energia. Estas consequências ambientais para a sociedade permitiriam reservar para os consumidores uma parcela suficientemente equitativa dos benefícios, mesmo levando em conta que os compradores de máquinas de lavar a roupa não obteriam vantagens individuais." ${ }^{\prime 35}$

Esta análise de custos e benefícios é uma característica que resulta também da necessária aplicação do princípio da proporcionalidade sempre que esteja em causa uma colisão entre uma restrição da concorrência e o cumprimento do objectivo ambiental fixados no acordo. A aplicação deste princípio na avaliação da aceitação ou proibição dos acordos ambientais é uma ferramenta da integração das preocupações ambientais no direito da concorrência.

Um acordo será proporcional se as suas cláusulas são adequadas, necessárias e razoáveis para atingir o fim proposto. Desta forma, as empresas partes no acordo têm de demonstrar não só que o disposto no acordo é pertinente para cumprir um objectivo de natureza ambiental mas também que foram ponderadas as várias alternativas para cumprir esse objectivo e escolhida

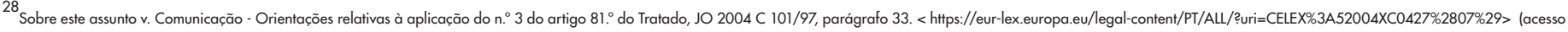
5 de Setembro 2021).

29

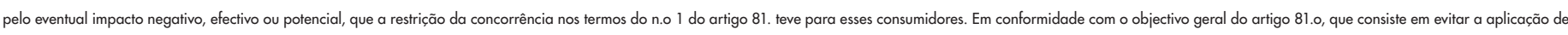

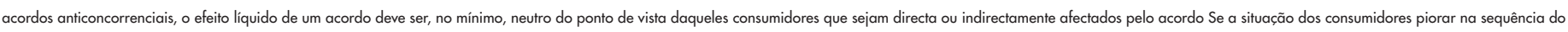

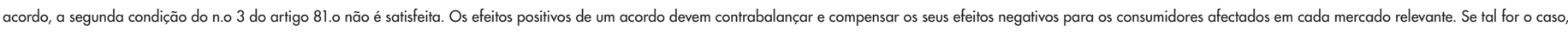
os consumidores não são prejudicados pelo acordo. <https://eur-lex.europa.eu/legal-content/PT/TXT/PDF/2uri=CELEX:52004XC0427(07)\&from=DA> (acesso 5 de Setembro 2021).

${ }^{30}$ Cf. Decisão da Comissão 2000/475/EC CECED [2000] L 187/47, parágrafo 53, <https://eur-lex.europa.eu/LexUriServ/LexUriServ.do?uri=OJ:L:2000:187:0047:0054:PT:PDF> (acesso 6 de Setembro 2021).

${ }^{31}$ Ibid., parágrafos $47-48$.

32 Ibid., parágrafo 51.

33 Ibid., parágrafo 48.

34 Ibid., parágrafo 52

35 Ibid., parágrafo 56.
} 
DOI: 10.46294/ulplr-rdulp.siv la 1

a alternativa menos lesiva tendo em conta uma avaliação de custos e benefícios para os consumidores e empresas concorrentes. Quando algum dos elementos que compõem o princípio da proporcionalidade não é assegurado pelo acordo, este não pode ser admitido à luz do direito da concorrência. No contexto desta avaliação de custos e benefícios, a Comissão Europeia faz uma diferenciação entre ganhos de eficiência de natureza qualitativa ou seja ganhos obtidos através da criação de produtos com novas características, com maior qualidade e eficiência e que podem advir, por exemplo, de acordos de investigação e desenvolvimento, por exemplo, e os ganhos de eficiência em termos de custos associados ao desenvolvimento de novas tecnologias e métodos de produção, como por exemplo a introdução de uma linha de montagem que proporciona uma redução substancial do custo de produção dos veículos a motor. ${ }^{36}$ Através destes instrumentos de cooperação entre empresas, que são os acordos ambientais, estas "podem conseguir gerar ganhos de eficiência que, na ausência de acordo restritivo, não seriam possíveis ou sê-lo-iam com um atraso considerável ou com custos mais elevados. Este tipo de ganhos de eficiência constitui uma importante fonte de benefícios económicos". ${ }^{37}$ Por outras palavras, os ganhos de eficiência provêm "de uma integração das atividades económicas que passa pela combinação dos activos das empresas, de modo a que estas possam alcançar, em conjunto, aquilo que mais dificilmente alcançariam isoladamente ou pela delegação noutra empresa de tarefas cuja realização pode ser mais eficientemente assegurada por essa empresa". ${ }^{38}$ Assim, podem não violar o direito da concorrência acordos de produção entre empresas que são concorrentes nos mercados em que se realiza a cooperação se o acordo permitir que as estas lancem um novo produto ou serviço que, se não fosse o acordo, não estariam em condições de lançar, devido, por exemplo, à sua capacidade técnica individual. ${ }^{39}$ Esta é também a opinião da Comissão na apreciação do acordo celebrado entre a Ford e a Volkswagen mediante o qual as duas empresas se comprometeram a produzir carros mais ecológicos. ${ }^{40}$

Este tipo de acordo de produção é propício a afectar de forma sensível a concorrência uma vez que as empresas fixam os níveis de produção, a qualidade, o preço dos bens "entre outros parâmetros concorrenciais". ${ }^{41}$ No entanto, se o acordo é flexível na medida em que as partes têm liberdade de escolher a forma de actuar para cumprir os objectivos ambientais fixados no acordo e permite que as partes "lancem um novo produto ou serviço que, com base em fatores objetivos, de outra forma não estariam em condições de lançar, por exemplo, devido à sua capacidade técnica" ${ }^{\prime \prime 2}$, então não será provável que os acordos de produção, entre empresas que são concorrentes nos mercados abrangidos pelo acordo, tenham efeitos restritivos na concorrência. ${ }^{43}$

Todavia, as partes no acordo devem provar, através da análise de custo e benefícios que os ganhos de eficiência são específicos ao acordo em causa e que não existem outras alternativas economicamente viáveis e menos restritivos da concorrência ou que as outras alternativas ponderadas, capazes de obter os mesmos benefícios ambientais que a alternativa escolhida, seriam mais dispendiosas economicamente. ${ }^{44}$

Do ponto de vista do consumidor comum a redução de preços que um acordo ambiental poderá proporcionar, será sempre um benefício. Em alguns casos é possível criar produtos mais ecológicos diminuindo os custos de produção, através de práticas de reciclagem e utilização dos restos de produção e de poupança do consumo de energia ou da utilização mais racional de outros recursos naturais. No entanto, quando se produzem produtos ou se fornecem serviços mais ecológicos nem sempre isso acontece. Por exemplo, os custos de produção de um produto

\footnotetext{
${ }^{36}$ Cf. Orientações relativas à aplicação do n. 3 do artigo $811^{\circ}$ do Tratado, parágrafos 59, 64, 67, 69 a 92

${ }^{37} \mathrm{Cf}$. Orientações relativas à aplicação do n. 3 do artigo $811^{\circ}$ do Tratado, paragrafo 70

${ }^{38} \mathrm{Cf}$. Orientações relativas à aplicação do n. 3 do artigo $811^{\circ}$ do Tratado, parágrafo 60.

${ }^{39}$ Cf. Comunicação da Comissão sobre a aplicação do artigo 101. o TFUE, parágrafo 163, <https://eur-lex.europa.eu/LexUriServ/LexUriServ.do?uri=OJ:C:2011:011:0001:0072:PT:PDF> (acesso 6 de Setembro 2021).

${ }^{40}$ Cf. Decisão da Comissão 93/49/CEE Ford/Volkswagen [1993] L 20/14, <https://eur-lex.europa.eu/legal-content/EN/TXT/?uri=CELEX\%3A31993D0049> (acesso 6 de Setembro 2021)

${ }^{41}$ Cf. Comunicação da Comissão sobre a aplicação do artigo $101^{\circ}$ do TFUE, parágrafo 157.

${ }^{42}$ Cf. Comunicação da Comissão sobre a aplicação do artigo $101^{\circ}$ do TFUE, parágrafo 163.

${ }^{43}$ Idem.

${ }^{44} \mathrm{Cf}$. Orientações relativas à aplicação do n. 3 do artigo $811^{\circ}$ do Tratado, parágrafos 73 a 75 e 79 .

45 Orientações relativas à aplicação do n. 3 do artigo $811^{\circ}$ do Tratado, parágrafo 104

${ }^{46}$ Orientaç̃̃es relativas à aplicação do n. 3 do artigo $811^{\circ}$ do Tratado, parágrafo 90

47 Orientaçẽes relativas à aplicação do n. 3 do artigo $811^{\circ}$ do Tratado, parágrafo 85

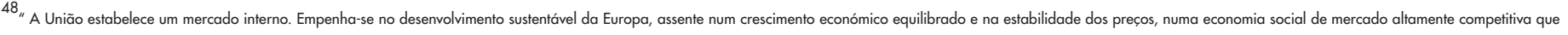

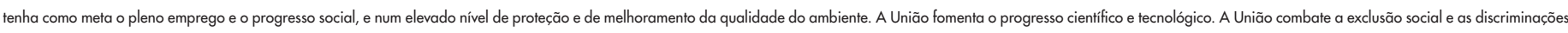
e promove a justiça e a proteção sociais, a igualdade entre homens e mulheres, a solidariedade entre as geraçães e a proteção dos direitos da criança." (artigo 3 , n 3 do TFUE).
} 
DOI: $10.46294 /$ ulplr-rdulp.siv 1 a 1

criado através de uma tecnologia inovadora com origem num grande investimento em investigação e desenvolvimento repercutem-se no preço final desse bem. Quando do acordo resultar um aumento dos preços para os consumidores "deve avaliar-se cuidadosamente se os alegados ganhos de eficiência criam um valor real para os consumidores nesse mercado que permita compensar os efeitos negativos da restrição de concorrência". ${ }^{45}$ Sempre que o acordo não tenha como consequência o aumento dos preços "quanto mais grave for a restrição da concorrência, maiores devem ser os ganhos de eficiência e a repercussão nos consumidores" $^{46}$

Ademais, na avaliação de custos e benefícios, o consumidor não é apenas a sociedade ou o consumidor do presente. Se a Comissão considera que "a sociedade em geral é beneficiada onde os ganhos de eficiência conduzem à utilização de menos recursos para produzir o bem consumido ou à produção de bens de maior valor e, portanto, a uma afetação mais eficiente dos recursos ${ }^{47}$, nessa avaliação têm de ser ponderados os benefícios e custos para as gerações presentes e futuras, em conformidade com o espírito do artigo $3 n^{\circ} 3$ do TUE ${ }^{48}$ e ao encontro do princípio da justiça intergeracional.
Ainda em conformidade com 0 artigo $101 \mathrm{n}^{\circ} 3$ do TFUE nenhum acordo, independentemente dos benefícios ambientais e económicos que se pretendam alcançar, poderá ser admitido se impedir a inovação tendente à produção de produtos ecológicos de empresas concorrentes.

A responsabilidade social corporativa não está apenas associada às ações de filantropia da empresa, mas também às relações de transparência com clientes e fornecedores, à qualidade dos produtos, à inovação tecnológica, à influência dos stakeholders nas decisões das empresas, ao investimento no capital humano e na segurança no trabalho, com respeito pela legislação ambiental, laboral e sobre os direitos dos animais. É nestes elementos que reside o sucesso da empresa face aos seus concorrentes e para o qual os acordos ambientais podem contribuir se forem cumpridos e não forem a expressão da sobreposição do poder dos grupos de interesse económico sobre a regulação. ${ }^{49}$ 
ULPLR I ULP LAW REVIEW I REVISTA DE DIREITO DA ULP

SPECIAL ISSUE I 2022

DOI: $10.46294 /$ ulplr-rdulp.siv 1 a 1

\section{Bibliografia}

ABREU, Lígia Carvalho (2020), Responsabilidade Social Corporativa no Setor da Moda e do Luxo: uma perspectiva jurídico-económica e sustentável. In Fashion Law. Direito da Moda. Thomson Reuters Aranzadi.

AUTORIDADE DA CONCORRÊNCIA. Práticas colusivas. Obtido de Autoridade da Concorrência: <http://www.concorrencia.pt/vPT/Praticas_Proibidas/ Praticas_Restritivas_da_Concorrencia/Praticas_Colusiva s/Paginas/Praticas-colusivas.aspx > (Acesso, 5 de Setembro 2021).

BERTONCELLO, Silvio L. T. e CHANG JUNIOR, João (2007), "A importância da responsabilidade social corporativa como factor de diferenciação" FACOM n. 17,1 semestre.

BOUTE, Anatole (2006), "Environmental Protection and EC Anti-Trust Law: The Commission's Approach for Packaging Waste Management Systems". RECIEL, n. ${ }^{\circ} 15(2)$, 146-159, https://www.researchgate.net/publication/230244486_Environmental_Protection_and_EC_Anti-Trust_Law_The_Commission's_ Approach_for_Packaging_Waste_Management_Systems

CABUGUEIRA, Manuel (2005), "Environmental Voluntary Agreements in Portugal: Characterisation and implementation." The Handbook of Environmental Voluntary Agreements: Design, Implementation and Evaluation Issues, E. Croci (Ed.), pp. 203-219.

CARROL, Archie (1979), "A Three dimensional conceptual model of corporate performance." Academy of Management Review (pre-1986); 4; ABI/INFORM Comunicação da Comissão ao Parlamento Europeu, ao Conselho, ao Comité Económico e social e ao Comité das Regiões - Acordos Ambientais concluídos a nível comunitário no âmbito do Plano de Acção "Simplificar e melhorar o ambiente regulador" COM (2002) 412 final, <https://eur-lex.europa. eu/legal-content/PT/TXT/PDF/?uri=CELEX:52002DC0412\&from=PT > lacesso 6 de Setembro 2021).

Comunicação da Comissão sobre a aplicação do artigo 101. o TFUE, parágrafo 163, <https://eur-lex.europa.eu/LexUriServ/LexUriServ. do?uri=OJ:C:2011:011:0001:0072:PT:PDF> (acesso 6 de Setembro 2021).

Comunicação da Comissão relativa aos acordos de pequena importância que não restringem sensivelmente a concorrência nos termos do $n^{\circ} 1$ do artigo $81^{\circ}$ do Tratado que institui a Comunidade Europeia (de minimis), [2001] JO C368/07, < https://eur-lex.europa.eu/legal-content/PT/ TXT/?uri=CELEX\%3A52014XC0830\%2801\%29> (Acesso 5 de Setembro 2021).

Comunicação da Comissão sobre o conceito de afetação do comércio entre os Estados-Membros previsto nos artigos $81 .^{\circ}$ e $82 .^{\circ}$ do Tratado JO 2004 C 101/07, < https://eur-lex.europa.eu/legal-content/PT/TXT/PDF/? uri=CELEX:52004XC0427/06)\&from=DA> (Acesso 5 de Setembro 2021).

Comunicação da Comissão - Orientações relativas à aplicação do n. 3 do artigo 81. . do Tratado JO 2004 C 101/08, <https://eur-lex.europa.eu/legalcontent/PT/TXT/PDF/?̣uri=CELEX:52004XC0427/07)\&from=DA> (acesso 5 de Setembro 2021).

Comunicação da Comissão relativa à definição de mercado relevante para efeitos do direito comunitário da concorrência JO 1997 C 372/03, < https:// eur-lex.europa.eu/legal-content/PT/TXT/?uri=celex:31997Y1209/01)> (acesso 6 de Setembro 2021).

Decisão da Comissão 2000/475/EC CECED [2000] L 187/47, <https://eur-lex.europa.eu/LexUriServ/LexUriServ.

do?uri=OJ:L:2000:187:0047:0054:PT:PDF> (acesso 6 de Setembro de 2021).

Decisão da Comissão 86/398/CEE Proliproleno [1986] JO L 230/1, <https://eur-lex.europa.eu/legal-content/PT/TXT/

PDF/? $u r i=C E L E X: 31986 D 0398 \& f r o m=E N>$ (acesso 5 de Setembro 2021). 
ULPLR I ULP LAW REVIEW I REVISTA DE DIREITO DA ULP

SPECIAL ISSUE I 2022

DOI: $10.46294 /$ ulplr-rdulp.siv 1 a 1

EUROPEAN ENVIRONMENT AGENCY (1997), "Environmental Agreements Environmental Effectiveness - Case Studies" Environmental Issues Series N. 3 , vol. 1. HILDEBRAND, D. (2009). The Role of Economic Analysis in the EC Competition Rules. Wolters Kluwer.

JONES, Alison (2012), "The boundaries of an undertaking in EU Competition Law." European Competition Journal, n. 8 (2), pp. 301-331, https://www. tandfonline.com/doi/abs/10.5235/ECJ.8.2.301

KERRET, Dorit e TAL, Alon, (2005). «Greenwash or Green Gain? Predicting the success and Evaluating the Effectiveness of Environmental Voluntary Agreements." Penn State Environmental Law Review, 14(84), 31-84, https://social-sciences.tau.ac.il/sites/socsci.tau.ac.il/files/media_server/social/public/ CV/alontal/19|\%20Greenwash\%20or\%20Green\%20Gain\%20-\%20Predicting\%20the\%20Effectiveness\%20of\%20Environmental\%20Agreements,\%20Penn\%20 State\%20Law\%20Review,\%202005.pdf (acesso 6 de Setembro)

KINGSTON, Suzanne (2012), Greening EU Competition Law and Policy. Cambridge University Press.

LAMEIRA, Elsa (2018), Os Acordos Ambientais entre Empresas no Direito da Concorrência da União Europeia,

dissertação em ciências jurídico empresariais, Universidade de Coimbra, <https://eg.uc.pt/bitstream/10316/85891/1/Disserta\%C3\%A7\%C3\%A30\%20 com\%20capa.pdf> (acesso 6 de Setembro 2021).

MONTI, Mario (2001) "Market definition as a cornerstone of EU Competition Policy" Workshop on Market Definition - Helsinki Fair Centre, Helsinki, < https://ec.europa.eu/commission/presscorner/detail/en/SPEECH_01_439> lacesso 6 de Setembro 2021).

REHBINDER, Eckard (1997), "Environmental Agreements - a New Instrument of Environmental Policy." Environmental Policy and Law (27), p. 7-37, <https:// cadmus.evi.eu/handle/1814/23649 > (acesso 6 de Setembro 2021).

SADELEER, Nicolas de (2014). EU Environmental Law and the Internal Market. Oxford University Press.

SERENS, Manuel (2017), Das Obrigações de Não Concorrência na Negociação Definitiva da Empresa. Almedina.

TOWNLEY, Christopher (2011). "Inter-generational Impacts in Competition Analysis: Remembering Those Not Yet Born."

European Competition Law Review, n. ${ }^{\circ} 32(11)$, 580-589, <https://www.academia.edu/774728/Inter-Generational_Impacts_in_Competition_Analysis_ remembering_those_not_yet_born> (acesso 6 de Setembro 2021)

VEDDER, Hans (2003), "Competition Law and Environmental Protection in Europe; Towards Sustainability?" Europa Law Publishing. <https://www. researchgate.net/publication/254853741_Competition_Law_and_Environmental_Protection_in_Europe_Towards_Sustainability> lacesso 6 de Setembro 20211 